\title{
ABORDAGENS TEÓRICAS DE TECNOLOGIA SOCIAL NO BRASIL
}

\author{
THEORETICAL APPROACHES OF SOCIAL TECHNOLOGY IN BRAZIL
}

\author{
Recebido em 05.04.2017. Aprovado em 06.09.2017 \\ Avaliado pelo sistema double blind review \\ DOI: http://dx.doi.org/10.12712/rpca.v11i5.962
}

\section{Thais Oliveira Duque}

Instituto Federal de Minas Gerais (IFMG), Bambuí/MG, BRASIL

adm.thaisduque@yahoo.com.br

\section{José de Arimatéia Dias Valadão}

Universidade Federal de Lavras (UFLA), Lavras/MG, BRASIL

arimateiavaladao@hotmail.com

\section{Resumo}

Cada vez mais as Tecnologias Sociais (TS) têm sido consideradas estratégicas para o desenvolvimento social no Brasil. Diante do esforço que tem sido feito atualmente na busca por um marco conceitual e analítico das TS, esse trabalho buscou mapear as concepções teóricas hoje existentes no contexto brasileiro. Para isso, foi utilizado a bibliometria como procedimento metodológico em três diferentes fases de análise. Na primeira análise foi possível concluir que existem duas visões sobre TS atualmente. As duas outras análises corroboraram as conclusões da primeira e mostrou que muito do que é discutido atualmente relaciona-se a uma ou outra visão. A primeira visão trata das TS como práticas que proporcionam transformações sociais em uma comunidade a partir da ação da própria comunidade, já a segunda trata as TS como artefatos geradores de mudanças sociais. Essas duas visões permearam as conceituações existentes nos trabalhos analisados, sendo que uma TS pode ser compreendida como TS quando gera transformações sociais condizentes com as aspirações da própria comunidade beneficiada.

Palavras-chave: Tecnologia social. Adequação Sociotécnica. Desenvolvimento Sustentável. Bibliometria.

\begin{abstract}
Increasingly, Social Technologies (TS) have been considered strategic for social development in Brazil. Faced with the effort that has been made in the search for a conceptual and analytical framework of TS, this work sought to map the theoretical conceptions that exist in the Brazilian context. For this, bibliometrics was used as a methodological procedure in three different phases of analysis. In the first analysis, it was possible to conclude that there are two views on TS today. The two other analyses corroborated the conclusions of the first and showed that much of what is currently discussed relates to one or another view. The first view treats the TS as practices that provide social transformations in a community from the action of the community itself, and the second treats TS as artefacts that generate social change. These two visions permeated the concepts existing in the analysed works, and a TS can be understood as TS when it generates social transformations that are in keeping with the aspirations of the beneficiary community itself.
\end{abstract}

Keywords: Social technology. Sociotechnical Adequacy. Sustainable Development Bibliometry. 


\section{Introdução}

As Tecnologias Sociais (TS) têm sido vistas, nas últimas décadas, como potencializadoras de transformações sociais. Grosso modo, as TS são construções comunitárias direcionadas a resolução de problemas sociais, econômicos e, dentre outros, ambientais, que possibilitam a inclusão social dos envolvidos (BAVA, 2004; FREITAS; SEGATO, 2014; PEYLOUBRT EL AL., 2010; RODRIGUES; BARBIERI, 2008; THOMAS, 2009). Além disso, tecnologia social é um conceito proposto para caracterizar uma tecnologia oposta à tecnologia convencional (DAGNINO, 2010). Entende-se por tecnologia convencional aquela que "visa ao lucro e tende a provocar a exclusão social" (DAGNINO, 2013, p. 253), enquanto a Tecnologia Social visa a inclusão social, a participação e a emancipação social, sendo conceituada como "construções coletivas direcionadas para a resolução de problemas socioambientais cotidianos por meio da interação, do conhecimento e das iniciativas das próprias comunidades locais que possibilitam a inclusão social, a autonomia, o desenvolvimento sustentável e a transformação social" (ANDRADE; VALADÃO, 2017, p. 408).

Os estudos referentes às TS foram alavancados, sobretudo no aspecto político, por uma rede de instituições que publicizaram o termo no País e trouxe visibilidade inclusive no âmbito de políticas públicas. É em decorrência, principalmente da atuação dessa rede, que tramita no Congresso Nacional, desde de 2011, a Política Nacional de Tecnologias Sociais, onde visa promover e potencializar as tecnologias sociais, dando tratamento idêntico às demais políticas desenvolvidas no âmbito da ciência, tecnologia e inovação no Brasil.

Para Albuquerque (2009), essa rede tratou de um "grande consórcio" que tinha como membros o Governo e entidades de cunho público e privado, como a Fundação Banco do Brasil (FBB), o Sebrae, a Petrobrás e diversas ONGs nacionais. Nessa rede destaca-se: i) a Fundação Banco do Brasil, orientada para a análise de iniciativas de desenvolvimento e reaplicação de Tecnologia Social com vistas à elaboração de políticas públicas (COSTA, 2013); ii) a Rede de Tecnologia Social que reúne, organiza, articula e integra um conjunto de instituições com o propósito de contribuir para a promoção do desenvolvimento sustentável, mediante a difusão e a reaplicação em escala de tecnologias sociais (SANTOS, 2008) e iii) o Instituto de Tecnologia Social, que tem como missão promover a geração, o desenvolvimento e o aproveitamento de tecnologias voltadas para o interesse social e reunir as condições de mobilização do conhecimento, a fim de atender às demandas da população (DAGNINO, 2010).

Dessas instituições, talvez a mais expressiva seja a Rede de Tecnologia Social (RTS), que desde 2004, como um todo, vêm se consolidando como um conjunto de projetos e instituições interconectados como agências e empresas de desenvolvimento (PAULA, 2009). A RTS colocou em pauta discussões a respeito dos modelos tecnológicos anteriores, questionando a conotação clássica das tecnologias convencionais e referenciando-as dentro de novos quadros de análise, reconhecidas hoje como TS (DAGNINO; BRANDÃO; NOVAES, 2004).

Cerca de seiscentas instituições fazem parte dessa rede, cujo objetivo é a promoção da sustentabilidade mediante a reaplicação de TS reconhecidamente potencializadoras de transformações sociais. Para Fonseca e Serafim (2009), as TS passaram ser reconhecidas, tanto no aspecto científico e tecnológico, como no âmbito da democracia participativa, como política de geração de emprego, renda e desenvolvimento social, sendo relevantes para elaboração de políticas públicas.

No âmbito acadêmico, há mais de uma década já se estimava que mais de quarenta universidades tinham alguma relação com os movimentos das Redes de Economia Solidária (RESs), com as Incubadoras Tecnológicas de Cooperativas Populares (ITCPs) e com a RTS de um modo geral (DAGNINO; BRANDÃO; NOVAES, 2004). Esse movimento da RTS tem influenciado vários grupos de pesquisa a produzir conhecimento que leve à reflexão sobre os rumos das TS no Brasil. Além disso, tem proporcionado a geração de inovação no âmbito das parcerias e inter-relações com movimentos sociais como "o movimento ambientalista, o movimento em favor da economia solidária, o movimento em favor do desenvolvimento local e o próprio movimento (político) em favor das tecnologias sociais" (PAULA, 2009, p. 136).

Concomitante a esse movimento, o número de publicações sobre tecnologias sociais tem crescido a cada ano no País. Com uma simples busca por "tecnologias sociais" no Google Acadêmico, tendo como critério de seleção o ano de 2000 , foi encontrado um número total de 16 publicações. Usando o mesmo 
critério de seleção, tendo o ano de 2014 como referência, esse número subiu para 724 publicações.

Desses trabalhos, um dos autores que mais circulam nas bibliografias de TS é o professor Renato Dagnino, do Departamento de Política Científica e Tecnologia da UNICAMP. Sejam em obras conjuntas com outros autores, individualmente ou como organizador, suas reflexões a respeito, sobretudo, do marco-analítico conceitual da Tecnologia Social é referência para boa parte da bibliografia relacionada às TS.

Além do pioneirismo de Dagnino, da repercussão política e do crescente interesse acadêmico por essa temática, uma questão que se levanta é: como tem ocorrido a produção científica sobre TS no Brasil? Essa foi a questão de pesquisa que norteou esse trabalho. Para isso, foi realizado um estudo bibliométrico em três fases, compreendendo o período de 2002 a 2015, tendo como base, além da presença do termo tecnologia social, o número de citações que compreendiam os trabalhos localizados. Para fazer essa discussão, o trabalho está dividido, além dessa introdução, em mais três seções. A próxima, que discute sobre o fenômeno das TS no Brasil. Uma outra, que apresenta os procedimentos metodológicos do trabalho. Além de outras duas que apresentam a análise dos dados obtidos e reflete sobre os achados da pesquisa. Uma última seção trata das conclusões do estudo.

\section{Tecnologias Sociais no Brasil}

Academicamente, alguns autores da Escola de Chicago, como Small (1898) e Henderson (1901), já descreviam, no final do século XIX, desenvolvimentos tecnológicos muito próximos das discussões atuais de TS. Ambos defendiam, como se discute hoje, uma sociologia inter-relacionada à materialidade do mundo em que os aspectos técnicos, materiais e sociais deveriam se constituir de maneira indissociada no contexto de uma comunidade. Para Henderson (1901, p. 471), tecnologias deveriam ser sociais, pois toda tecnologia deveria ser

[...] um sistema de organização consciente e proposital de pessoas, em que cada organização social, real e natural encontra seu verdadeiro lugar, e todos os fatores em harmonia cooperam para realizar um conjunto cada vez maior e em proporções mais desejadas de "saúde, riqueza, beleza, conhecimento, sociabilidade e equidade".

Politicamente, Sarovaya Gandhi na Índia, nesse mesmo período histórico, já defendia uma política científica e tecnológica que fosse coerente com os modelos produtivos, as condições econômicas e sociais das comunidades artesãs. Para Herrera (2010), Gandhi defendia que toda tecnologia deveria ser "apropriada" contextualmente em um enfoque integrado de desenvolvimento social, econômico e cultural local.

Críticas e alternativas tecnológicas como essas citadas foram relevantes para que na segunda metade do Século XX se consolidasse modelos contrários às tecnologias convencionais, registrados na literatura geralmente como tecnologias apropriadas (TA) (RYBCZYNSKI, 1980; AKUBUE, 2000) e tecnologias intermediárias (TI) (SCHUMACHER, 1977). Herrera (2010, p. 2) fala que

A tecnologia intermediária [...] foi proposta por Schumacher em meados dos anos 1960. Refere-se a uma tecnologia que requer menos inversão de capital para cada posto de trabalho que a correntemente em uso. Deveria ser em pequena escala, descentralizada, com relevância rural, baseada em recursos locais e de funcionamento e manutenção simples. Tecnologia apropriada foi usada pelos planejadores indianos no início dos anos 1960 com significado, na prática, muito similar ao proposto por Schumacher, de tecnologia intermediária.

As décadas de 1970 e 1980 foram intensas de desenvolvimento de modelos tecnológicos aproximados das conceituações de TA, ou seja, baseados em produção em pequena escala, para uso familiar ou comunitário, não alienantes e de baixo custo. As TA foram "[...] importante nos modelos de desenvolvimento econômico à sua época, uma vez que possibilitava tecnologias àqueles que não poderiam acessar as tecnologias desenvolvidas pelos modos convencionais" (SILVA, 2012, p. 35). Contudo, 
principalmente os programas institucionais, das quais as transferências desses modelos se baseavam, como era o caso no Brasil do Programa de Transferência de Tecnologias Apropriadas (PTTA) sob responsabilidade do CNPq, já mostravam, ao final da década de 1980, sinais esgotamento. Esse esgotamento se dava, dentre outros aspectos, pelas duras críticas que sofriam (GARCIA, 1987). Para Silva (2012, p. 35) “[...] a TA atendia ao sentimento de culpa dos pesquisadores do Primeiro Mundo, que se mantinham distantes do público que queriam beneficiar". Em um Seminário sobre tecnologias apropriadas, realizado em São Paulo, nos dias 26 e 27 de setembro de 1985, Garcia (1987) enumerou algumas dessas críticas (quadro 1).

Quadro 1. Críticas à Tecnologia Apropriada.

\begin{tabular}{|c|c|}
\hline Crítica & Conteúdo \\
\hline Unidimensional & $\begin{array}{l}\text { Vocês estão complicando } \\
\text { demais a questão"; "Para que } \\
\text { esta "doidura" de variáveis } \\
\text { sociais, políticas e ecológicas?"; } \\
\text { "Tecnologia é tecnologia - ora! - é } \\
\text { apenas um fator de produção". }\end{array}$ \\
\hline Imponente & $\begin{array}{l}\text { "Tecnologia é algo que se adquire } \\
\text { no mercado internacional, } \\
\text { produzida por nações mais } \\
\text { poderosas e de maiores recursos". }\end{array}$ \\
\hline Inautêntica & $\begin{array}{l}\text { "Os países subdesenvolvidos não } \\
\text { têm capacidade para produzir } \\
\text { uma tecnologia realmente } \\
\text { significativa". }\end{array}$ \\
\hline Paradigmática & $\begin{array}{l}\text { "O paradigma tecnocrático } \\
\text { tem como objetivo central de } \\
\text { investigação o mercado. Este } \\
\text { é visto como constituído de } \\
\text { inúmeros agentes que realizam } \\
\text { transações exclusivamente como } \\
\text { produtores ou consumidores. Isto } \\
\text { implica que todo comportamento } \\
\text { econômico seja visto como } \\
\text { comportamento de mercado e } \\
\text { que toda decisão econômica seja, } \\
\text { direta ou indiretamente, uma } \\
\text { decisão de mercado". }\end{array}$ \\
\hline Nominalista & $\begin{array}{l}\text { "A tecnologia apropriada não } \\
\text { existe."; "Tem muitos nomes } \\
\text { diferentes."; "Vocês, adeptos da } \\
\text { tecnologia apropriada, nem sabem } \\
\text { o que ela é - são incapazes de } \\
\text { defini-la". }\end{array}$ \\
\hline
\end{tabular}

\begin{tabular}{|c|c|}
\hline Pseudorealista & $\begin{array}{l}\text { "A proposta da tecnologia } \\
\text { apropriada é ingênua."; "É } \\
\text { inviável e romântica". "É } \\
\text { saudosista e retrógrada, pois } \\
\text { propõe um retorno às formas de } \\
\text { vida e de produção tradicionais e } \\
\text { pouco produtivas." }\end{array}$ \\
\hline Maniqueísta & $\begin{array}{l}\text { "Em verdade, o que se quer com } \\
\text { a tecnologia apropriada é impedir } \\
\text { o desenvolvimento dos países do } \\
\text { Terceiro Mundo."; "Não querem } \\
\text { que a gente chegue lá."; "Não } \\
\text { se quer um desenvolvimento } \\
\text { econômico compatível com os } \\
\text { padrões internacionais". }\end{array}$ \\
\hline Pseudoprogressista & $\begin{array}{l}\text { "A tecnologia apropriada reforça } \\
\text { o "gap" tecnológico entre os } \\
\text { povos do Terceiro Mundo } \\
\text { e as nações desenvolvidas."; } \\
\text { "Consolida a dependência e a } \\
\text { organização internacional do } \\
\text { trabalho."; "Condena os países } \\
\text { do Terceiro Mundo a serem } \\
\text { exportadores de produtos pouco } \\
\text { elaborados e de baixa densidade } \\
\text { tecnológica". }\end{array}$ \\
\hline
\end{tabular}

Fonte: Garcia (1987, p. 27-28).

O enfraquecimento das TA fez emergir novas visões sobre as formas de desenvolvimento tecnológico, alternativas às tecnologias convencionais. Algumas delas ficaram conhecidas na literatura como tecnologias voltadas para a base da pirâmide (PRAHALAD; HART, 2002; PRAHALAD, 2005; HALL; MATOS; MARTIN, 2014), inovações sociais (MARTIN; OSBERG, 2007; MACLEAN; HARVEY; GORDON, 2013), grassroot inovations (GUPTA, SINHA; JORADIA; et al, 2003) e, dentre outras, tecnologias sociais (DAGNINO, BRANDÃO; NOVAES, 2004; DIAS; NOVAES, 2010; THOMAS; FRESSOLI, 2010; DAGNINO, 2010; HERRERA, 2010; THOMAS, 2009; FONSECA, 2009).

As TS, principalmente no âmbito do Banco do Brasil, da RTS e do ITS, além de outros espaços em que as TS têm sido discutidas, são conceituadas como "[...] produtos, técnicas ou metodologias replicáveis, desenvolvidas na interação com a comunidade e que representem efetivas soluções de transformação social" (RODRIGUES; BARBIERI, 2008; 1070). Para Thomas (2009, p. 2) “[...] é possível definir 
tecnologia social como uma forma de desenhar, desenvolver, implementar e gerir tecnologia orientada a resolver problemas sociais e ambientais, gerando dinâmicas sociais e econômicas de inclusão social e desenvolvimento sustentável”.

Contrárias às abordagens convencionais de tecnologia, que pauta as inovações tecnológicas por meio de programas de P\&D, uma TS baseia-se em produção comunitária e pressupõe uma simetria entre o conhecimento tradicional e comunitário e o conhecimento científico. Desse modo, a TS é "caracterizada pela heterogeneidade, orientada por problemas, enfatizando o contexto de aplicação e transcendendo fronteiras disciplinares" (Garcia, 2014, p. 257). Para Rodrigues e Barbieri (2008, p. 1075), uma TS "implica a construção de soluções de modo coletivo pelos que irão se beneficiar dessas soluções e que atuam com autonomia”. Bava (2004, p. 116) salienta que as TS,

[...] mais do que a capacidade de implementar soluções para determinados problemas, podem ser vistas como métodos e técnicas que permitam impulsionar processos de empoderamento de representações coletivas da cidadania para habilitá-las a disputar, nos espaços públicos, as alternativas de desenvolvimento que se originam das experiências inovadoras e que se orientem pela defesa dos interesses das maiorias e pela distribuição de renda.

Essa compreensão das TS tem levado as instituições, como o ITS e a RTS, e os grupos de pesquisa envolvidos, a empregarem esforços na busca por um marco analítico conceitual das TS no Brasil. $\mathrm{Na}$ construção desse marco conceitual, contudo, se por um lado está bem claro o avanço que as TS representam face às abordagens anteriores, por outro ainda mostra limitações conceituais ao focar, em muitos casos, unicamente em técnicas e metodologias apropriadas às comunidades locais (OTTERLOO, 2009; DAGNINO, 2010; VALADÃO, 2014). A compreensão de como tem se dado a produção de conhecimento, dentre outras formas, por meio da análise da bibliografia gerada nas últimas décadas pode, de uma forma ou de outra, contribuir para o avanço da construção desse marco analítico e conceitual das TS no Brasil.

\section{Procedimentos Metodológicos}

Bibliometria é a "técnica quantitativa e estatística de medição dos índices de produção e disseminação do conhecimento científico" (ARAÚJO, 2006, p. 12). Essa técnica é utilizada para "mapear os registros bibliográficos a fim de estabelecer padrões e até mesmo conceituar, quantificar e qualificar a produtividade no campo científico" (BERNARDINO;CAVALCANTE, 2011, p. 255). "A área mais importante da bibliometria é a análise de citações" (ARAÚJO, 2006, p. 18).

Araújo (2006, p. 19) ratifica que

$$
\begin{aligned}
& \text { Com os dados retirados das } \\
& \text { citações pode-se descobrir: } \\
& \text { autores mais citados, autores mais } \\
& \text { produtivos, elite de pesquisa, } \\
& \text { frente de pesquisa, fator de } \\
& \text { impacto dos autores, procedência } \\
& \text { geográfica e/ou institucional dos } \\
& \text { autores mais influentes em um } \\
& \text { determinado campo de pesquisa; } \\
& \text { tipo de documento mais utilizado, } \\
& \text { idade média da literatura utilizada, } \\
& \text { obsolescência da literatura, } \\
& \text { procedência geográfica e/ } \\
& \text { ou institucional da bibliografia } \\
& \text { utilizada; periódicos mais citados, } \\
& \text { "core" de periódicos que compõem } \\
& \text { um campo. }
\end{aligned}
$$

A análise de citações "é medida pela quantidade de citações, o que, por sua vez, não garante qualidade no que diz respeito ao tema abordado. Por outro lado, valida o trabalho ou a pesquisa através da avaliação dos pares e do número de citações recebidas" (BERNARDINO; CAVALCANTE, 2011, p. 255). Um exemplo, é a bibliometria realizada por Peres Júnior e Pereira (2014), onde definiram as correntes teóricas da gestão social no Brasil. Utilizaram, para isso, um "levantamento bibliométrico, mais especificamente de uma análise de citações exploratórias, que buscava identificar os autores e os trabalhos de maior impacto da área [...]" (PERES JÚNIOR; PEREIRA, 2014, p. 222).

Percorrendo um caminho metodológico semelhante ao de Peres Júnior e Pereira (2014), neste trabalho analisaram-se correntes teóricas que definem a Tecnologia Social, utilizando-se os seguintes critérios: a) Identificação de artigos publicados entre os anos 
de 2002 e 2015, com número superior a 30 citações; b) Identificação de artigos publicados entre os anos de 2011 e 2015, com número superior a 10 citações; c) Identificação de artigos publicados entre os anos de 2011 e 2015, que tinham no título o termo tecnologia social.

Foi utilizado o Google Acadêmico como ferramenta de suporte. A escolha desta ferramenta de busca se justifica pelo fato de as produções sobre tecnologias sociais ocorrerem, em muitos casos, voltadas para atores não diretamente acadêmicos, como é o caso de movimentos sociais, cooperativas populares, organizações não governamentais, divisões governamentais e empresas públicas (THOMAS, 2009) não sendo as produções científicas publicadas, muitas vezes, nas tradicionais bases de dados acadêmicas.

O termo para as três etapas da pesquisa foi "tecnologia social", entre aspas, o que indica a busca pela expressão ou frase exata. Nas etapas 1 e 2 , o termo poderia ser identificado em qualquer lugar do documento e, na etapa 3, somente no título do documento. Apesar de ser uma evidente limitação a escolha somente de bases nacionais, mas o objetivo principal da pesquisa consistiu em compreender a produção científica sobre TS no contexto brasileiro, por isso a busca foi realizada somente com o termo em português e em bases nacionais.

\section{Procedimentos de Análise}

A seguir são apresentadas três análises. A função da primeira análise foi definir o significado atribuído à tecnologia social. A segunda análise privilegiou a separação de trabalhos entre as visões identificadas na primeira análise. A terceira análise tratou de agrupar os trabalhos. O critério utilizado para criar os grupos foi a base teórica utilizada.

Todas as buscas, nas diversas fases da pesquisa, foram realizadas unicamente pelo primeiro autor. As análises, contudo, ocorreram entre os dois autores, com um encontro semanal, durante dois meses (agosto e setembro de 2015), totalizando 9 encontros. Cada encontro durou aproximadamente duas horas com a seguinte metodologia: primeiro, apresentação dos trabalhos localizados; segundo, apresentação de cada trabalho e análise de seu conteúdo e discussão; terceiro, realização de aproximações e afastamento entre os trabalhos e; por último, conclusões sobre as discussões e análises. O primeiro encontro ocorreu a partir da primeira busca e do conjunto inicial de trabalhos localizados.

Na primeira análise, o recorte temporal de 2002 a 2015, se deu, pois, a maioria das referências teóricas sobre TS datam a partir do início desse período. Como as demais análises visavam confirmar a existência atualmente das duas visões identificadas na primeira análise, a escolha temporal se deu a partir da análise das publicações dos últimos cinco anos.

\section{Primeira análise}

A primeira busca foi realizada dia 28 de julho de 2015, utilizando-se o termo "tecnologia social" (buscando a frase exata), identificando artigos publicados entre os anos de 2002 e 2015. O resultado da busca exibiu 4.560 trabalhos. A partir do resultado da busca, foram selecionados apenas os trabalhos que tinham número superior a 30 citações. O próximo passo foi constituído da leitura dos trabalhos e da identificação do significado atribuído à tecnologia social.

$\mathrm{Na}$ Tabela 1 exibem-se o ranking, os trabalhos e o número de citações de cada trabalho. Foram elencados 18 trabalhos.

Tabela 1. Trabalhos de maior impacto no campo da Tecnologia Social - Google Acadêmico - julho 2015

\begin{tabular}{clcc}
\hline Ranking & \multicolumn{1}{c}{ Referência } & Citações & $\begin{array}{c}\text { Inclusão/ } \\
\text { Exclusão }\end{array}$ \\
\hline 1 & SINGER, 2008. & 484 & Inclusão \\
2 & AYRES, 2004. & 426 & Exclusão \\
3 & DAGNINO, & 160 & Inclusão \\
& BRANDAO, & & \\
& NOVAES, 2004. & & Inclusão \\
4 & DAGNINO, 2004. & 112 & Exclusão \\
5 & LINSINGEN, & 89 & Inclusão \\
6 & 2007. & & Inclusão \\
7 & DAGNINO, 2009. & 81 & Exclusão \\
8 & BAVA, 2004. & 62 & Inclusão \\
& 2004. & 60 & \\
9 & LASSANCE & 56 & \\
& JÚNIOR, & & \\
10 & PEDREIRA, 2004. & & ELIVEIRA, 2004. \\
\end{tabular}




\begin{tabular}{|c|c|c|c|}
\hline 11 & $\begin{array}{l}\text { CANCCADO, } \\
\text { TENÓRIO, } \\
\text { PEREIRA, } 2011 .\end{array}$ & 49 & Exclusão \\
\hline 12 & $\begin{array}{l}\text { BURGESS, } \\
\text { GREEN, } 2009 .\end{array}$ & 47 & Exclusão \\
\hline 13 & $\begin{array}{l}\text { RODRIGUES, } \\
\text { BARBIERI, } 2008 .\end{array}$ & 46 & Inclusão \\
\hline 14 & $\begin{array}{l}\text { KERSTENETZKY, } \\
2006 .\end{array}$ & 43 & Exclusão \\
\hline 15 & $\begin{array}{l}\text { LIANZA, ADDOR, } \\
2005 .\end{array}$ & 42 & Exclusão \\
\hline 16 & ROSE, 2008. & 41 & Exclusão \\
\hline 17 & $\begin{array}{l}\text { GUIMARÃES, } \\
\text { FERREIRA FILHA, } \\
2006 .\end{array}$ & 37 & Exclusão \\
\hline 18 & ABRANTES, 2005. & 37 & Exclusão \\
\hline
\end{tabular}

Fonte: Elaborado pelos autores.

As considerações sobre as obras identificadas remetem ao seu conteúdo e à sua contribuição sobre o tema Tecnologia Social. Os trabalhos 2, 5, 8, 10, 11, 12, 14, $15,16,17$ e 18 foram descartados da análise por não se relacionarem ao conteúdo de tecnologias sociais e também por não apresentarem contribuições para as considerações acerca do objetivo da análise.

A exclusão se justificou, pois, o trabalho 2 apresenta como objetivo a consolidação de práticas de saúde pública, sendo que o termo tecnologia social aparece no artigo para evidenciar o termo cuidado pessoal. O trabalho 5 relata perspectivas educacionais e o termo tecnologia social é apenas citado como tema de pesquisa em instituições de ensino. $O$ trabalho 8 trata da crise nas escolas e o termo tecnologia social é evidenciado apenas nas referências bibliográficas. Esse é o caso também dos trabalhos 11, que trata de gestão social e do trabalho 12 , que trata de mídias sociais. O trabalho 10 apresenta contribuições acerca do tema empreendedorismo e realidade brasileira. Nesse, o termo tecnologia social é citado para caracterizar, especificamente, o empreendedorismo. $\mathrm{O}$ trabalho 14, sobre políticas sociais, discute a focalização, universalização, justiça distributiva e estado de bemestar, quanto ao termo tecnologia social não existe conceituação. $O$ trabalho 15 sobre tecnologia e desenvolvimento social não apresenta um conceito para o termo tecnologia social. Esse é o caso também dos trabalhos 16, sobre psicologia como uma ciência social, o trabalho 17 , sobre terapia comunitária, e o trabalho 18 , que relata os problemas nas transições entre ciclos de ensino. Nesses trabalhos o significado do termo tecnologia social não é apresentado.

Quanto aos trabalhos que foram incluídos na pesquisa, o trabalho 1 é uma entrevista com o professor Paul Singer e o tema central é Economia Solidária. A contribuição para a tecnologia social é apresentada de maneira superficial, principalmente quando o autor, em uma de suas respostas, relata que "Existe uma rede, hoje, de tecnologia social que o governo sustenta e que existe precisamente para criar e difundir tecnologias para a inclusão social" (SINGER, 2008, p. 310). Ao ser indagado sobre a importância de tecnologias desenvolvidas pelas universidades para o uso na economia solidária, o autor refuta que seja viável a implantação dessas tecnologias, devido ao elevado custo de implantação.

O trabalho 3 apresenta dois objetivos, que são perpetrar a definição do termo tecnologia social e apresentar a função da Rede de Tecnologia Social (RTS). Os autores desse trabalho apresentam a tecnologia social como sendo um artefato socialmente construído. Para os autores, “[...] o marco da tecnologia social dá atenção ao processo, ao caminho que uma configuração sociotécnica vai desenhando ao longo de um percurso que não tem cena de chegada definida" (DAGNINO; BRANDÃO; NOVAES, 2004, p. 42). Neste contexto, a tecnologia social surge na comunidade e não é possível sua replicação, ou seja, não pode ser reproduzida porque os atores envolvidos no processo social modificam seu teor conforme suas necessidades. Esse processo se dá por meio de adequação sociotécnica. A replicação neste contexto difere da reaplicação, pois a replicação seria a cópia exata sem alterações, como se pressupõem nos modelos tecnológicos convencionais. A reaplicação consiste na produção e reprodução de tecnologias a partir das dinâmicas e lógicas específicas das comunidades envolvidas com essas tecnologias.

No trabalho 4, Dagnino (2004, p. 7) faz uma diferenciação entre a tecnologia convencional e a tecnologia social, relatando que a tecnologia social apresenta características como “[...] adaptada a pequeno tamanho físico e financeiro; não discriminatória (patrão $\times$ empregado); orientada para o mercado interno de massa; liberadora do potencial e da criatividade do produtor direto; capaz de viabilizar economicamente os empreendimentos auto gestionários e as pequenas empresas".

O trabalho 6 é um livro composto por trabalhos apresentados e discutidos no Seminário Tecnologia 
para a Inclusão Social e Políticas Públicas na América Latina. Esse é um evento realizado no Rio de Janeiro, em 24 e 25 de novembro de 2008. No total, são seis trabalhos. O primeiro, "Contribuições ao Marco Analítico-Conceitual da Tecnologia Social”, reforça a proposição, já exposta por Dagnino (2004), de que a tecnologia social deve ser socialmente construída por seus usuários, utilizando a adequação sociotécnica como engrenagem de construção do artefato. O segundo e o terceiro, "Contribuições da Economia da Inovação para a Reflexão acerca da Tecnologia Social" e "Em direção a uma teoria crítica da tecnologia", reforçam o conceito de tecnologia social. Os três últimos trabalhos remetem à aplicação metodológica e política das tecnologias sociais.

O trabalho 7 tem como título "Tecnologia social e desenvolvimento local" e sua ideia central é a de que as tecnologias sociais são métodos ou técnicas para o desenvolvimento social. Bava (2004, p. 166) ratifica que

As tecnologias sociais - mais do que a capacidade de implementar soluções para determinados problemas, podem ser vistas como métodos e técnicas que permitam impulsionar processos de empoderamento das representações coletivas da cidadania para habilitá-las a disputar, nos espaços públicos, as alternativas de desenvolvimento que se originam das experiências inovadoras e que se orientem pela defesa dos interesses das maiorias e pela distribuição de renda.

No trabalho 9, Lassance e Pedreira (2004) consideram a tecnologia social como sendo uma base de articulação do social. Nesse contexto, as tecnologias sociais deveriam ter estruturas flexíveis, o que possibilitaria a sua reaplicação em realidades diversas. Os autores afirmam que "nem tudo que é viável em um lugar pode sê-lo, da mesma forma, em outro" (LASSANCE; PEDREIRA, 2004, p. 68). Ou seja, uma tecnologia social que obteve êxito em determinada comunidade pode precisar de adequações para se adaptar a outra comunidade. Os autores consideram que

Adaptações inteligentes e espírito inovador explicam por que se fala em reaplicação, e não em replicação, de Tecnologias Sociais (TS). Por outro lado, é também impossível disseminar uma determinada TS se não há um padrão tecnológico cujos elementos essenciais permitam escala. Considere-se que, no padrão tecnológico, o mais importante para a reaplicação pode ser, por exemplo, um programa de formação e capacitação, e não necessariamente um componente mecânico ou eletrônico. (LASSANCE; PEDREIRA, 2004, p. 68).

No trabalho 13, a tecnologia social "implica a construção de soluções de modo coletivo pelos que irão se beneficiar dessas soluções e que atuam com autonomia, ou seja, não são apenas usuários de soluções importadas ou produzidas por equipes de especialistas" (RODRIGUES; BARBIERI, 2008, p. 1075). Os autores propõem que as tecnologias sociais devem atender às demandas sociais concretas da população. O processo de tomada de decisão deve ser democrático e deve mobilizar a população. A população deve aprender e o aprendizado deve ser planejado e articulado. As tecnologias sociais devem ser sustentáveis no âmbito econômico, social e ambiental (RODRIGUES; BARBIERI, 2008).

Observa-se que o maior número de obras concentrase no ano de 2004, tendo em 2008 dois trabalhos e um trabalho no ano de 2009. Entre os anos de 2010 e 2015 não foram encontrados trabalhos com mais de 30 citações. Conclui-se, baseando nesse primeiro levantamento, que foi possível identificar duas visões para a conceituação de TS. São elas:

a) Uma visão, na qual a tecnologia social não é só um artefato, mas integra tudo que acontece na comunidade. Essa visão trata as TS como construções sociais que podem ser reaplicadas por meio da adequação sociotécnica. Foi possível notar que os trabalhos relacionados ao autor Renato Dagnino muito discutem as TS a partir dessa visão.

b) Há outra visão, em que as TS se baseiam em tecnologias para o social. Para essa visão, as TS significam articulações, programas e artefatos 
que, introduzidos no ambiente social, podem melhorar a vida da sociedade. Nota-se que os trabalhos que se aproximam da discussão de Silvio Caccia Bava, traz geralmente essa conceituação de TS.

Os trabalhos 3, 4, 6, 9 e 13 se aproximam da primeira visão. É importante ressaltar que a maioria dos trabalhos é de autoria de Dagnino ou de parcerias com outros autores (trabalhos 3, 4 e 6 ). O professor Renato Dagnino é professor titular no Departamento de Política Científica e Tecnológica da Unicamp e tem atuado como professor convidado em várias universidades no Brasil e no exterior. Atua na área Ciência-Tecnologia-Sociedade, com grande destaque, desde 1979.

Os trabalhos 1 e 7 aproximam-se mais da segunda visão. Destaca-se o trabalho 7 , com 62 citações, do autor Silvio Caccia Bava, sociólogo que, atualmente, integra o Conselho de Desenvolvimento Econômico e Social do município de São Paulo. Tem publicado extensivamente sobre temas como movimentos sociais, participação cidadã, desenvolvimento local, crise sistêmica e novos paradigmas. Nesta primeira análise é possível observar os significados atribuídos ao termo tecnologia social. Na Figura 3 evidenciam-se as conclusões propostas.

Figura 1. Visões em que se baseiam a conceituação de TS.

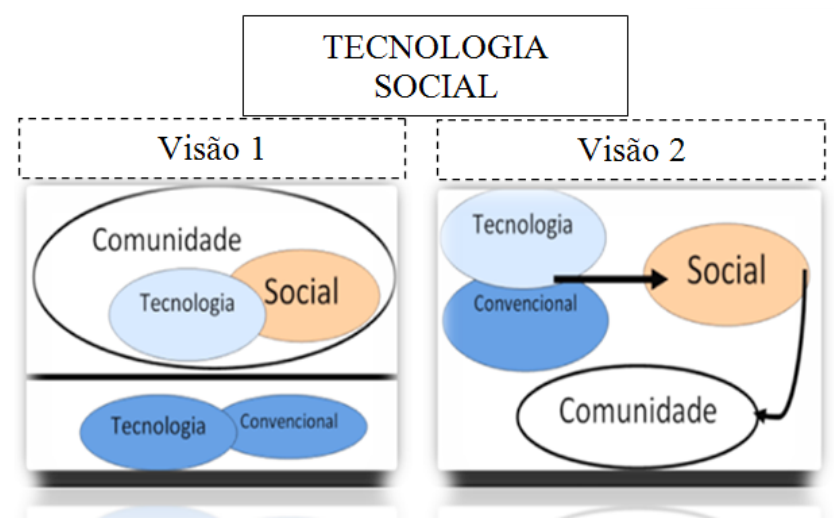

Fonte: Elaborado pelos autores.

Do lado esquerdo da Figura 3, a representação remete às tecnologias sociais na visão 1 . São tecnologias que surgem ou são adequadas na comunidade. Existe uma oposição total às tecnologias convencionais. Do lado direito, está representada a visão 2. As tecnologias convencionais são utilizadas com finalidade social. A introdução na comunidade acontece de maneira pontual, ou seja, a comunidade não, necessariamente, é parte integrante do processo de construção da tecnologia. As duas formas de caracterização da Tecnologia Social, assim como na Figura 3, refletem seu significado em outros artigos. A análise a seguir ratifica a existência dessas duas visões nos trabalhos que abordam a conceituação de TS.

\section{Segunda análise}

A segunda forma de busca, também com o termo "tecnologia social", foi feita no dia 4 de agosto de 2015, com artigos publicados entre os anos de 2011 e 2015 (últimos 5 anos). O resultado exibiu 2.570 trabalhos. Nesta segunda pesquisa foram considerados trabalhos com um número superior a 10 citações. A leitura privilegiou a separação de trabalhos que: i) consideram a tecnologia social uma construção social promovida por seus usuários por meio de reaplicação e os que ii) consideram a tecnologia social apenas um artefato ou ferramenta para promover avanços sociais. $\mathrm{Na}$ Tabela 2 exibem-se os trabalhos ranqueados segundo o número de citações de cada trabalho. Foram elencados nove trabalhos.

Tabela 2 . Trabalhos de maior impacto no campo da Tecnologia Social Google Acadêmico - agosto 2015

\begin{tabular}{clcc}
\hline Ranking & \multicolumn{1}{c}{ Referência } & Citações & $\begin{array}{c}\text { Inclusão/ } \\
\text { Exclusão }\end{array}$ \\
\hline 1 & CANÇADO, & 49 & Exclusão \\
& TENÓRIO, & & \\
& PEREIRA, 2011. & & \\
2 & BIGNETTI, 2011. & 28 & Inclusão \\
3 & DIAS, 2012. & 25 & Exclusão \\
4 & LUZ, 2011. & 20 & Inclusão \\
5 & LORENZETTI, & 16 & Inclusão \\
& 2012. & & \\
6 & LOPES, 2011. & 15 & Inclusão \\
7 & GUIMARÃES, & 15 & Exclusão \\
& GIORDAN, 2011. & &
\end{tabular}




$\begin{array}{llll}8 & \text { VILLAS-BÔAS, } & 12 & \text { Exclusão } \\ & \text { 2012. } & & \\ 9 & \text { CHRISPINO, } & 11 & \text { Inclusão } \\ & \text { SANTOS, 2011. } & & \end{array}$

Fonte: Elaborado pelos autores.

O objetivo da segunda análise foi entender como é utilizado o termo tecnologia social. Todos os trabalhos que atribuíram significado para o termo foram analisados, incluindo os que não tinham como foco principal as tecnologias sociais. Foram descartados da análise os trabalhos 1, 3, 7 e 8, por não apresentarem esses significados. No trabalho 1 , o termo tecnologia social aparece apenas no referencial teórico. No trabalho 3, o termo tecnologia social é referido como sendo um movimento. No trabalho 7, o termo é evidenciado separadamente sendo tecnologia e social. E no trabalho 8, o termo aparece apenas no referencial teórico.

Quanto às inclusões, o trabalho 2 tem como objetivo explicar "como se processa a gestão de inovações sociais contribuindo, assim, para o estabelecimento de marcos teóricos e referenciais sobre o tema" (BIGNETTI, 2011, p. 4). O autor argumenta sobre os preceitos teóricos da inovação. A base teórica é o contexto exposto por Schumpeter. O significado da inovação social, para Bignetti (2011), se aproxima muito do significado dado por Dagnino (2004) para a tecnologia social. A inovação social é um processo de construção social em que a "concepção, o desenvolvimento e a aplicação estão intimamente imbricados e são realizados através da relação e da cooperação entre todos os atores envolvidos" (BIGNETTI, 2011, p. 7). Essa concepção se aproxima da visão 1 e está estreitamente ligada às discussões realizadas, principalmente por Dagnino e seus colegas.

Apesar de o trabalho não trazer como foco principal a tecnologia social, o autor expõe seu posicionamento sobre o tema quando menciona que

É importante ressaltar mais uma vez que, se a inovação tecnológica e a inovação social possuem características distintivas, como apresentado, elas não representam dois conjuntos mutuamente excludentes. Ao contrário, é indiscutível que muitas inovações tecnológicas possuem caráter social e que inovações sociais podem lançar mão da tecnologia, particularmente no emprego das chamadas tecnologias apropriadas ou, mais amplamente, das tecnologias sociais (BIGNET'TI, 2011, p. 7).

Compreende-se também que Bignetti (2011) atribui às tecnologias sociais a função de ferramenta para a inovação social. O autor evidencia que elas são um conjunto de tecnologias apropriadas com características paternalistas orientadas para problemas pontuais. Dessa forma, descaracteriza o significado dado na visão 1e se aproxima da visão 2 , quanto à função de uma tecnologia para resolver problemas sociais. Contudo, nota-se claramente que as duas visões circunscrevem a discussão que Bignetti faz das TS.

O trabalho 4 tem como objetivo mostrar a importância e a legitimidade do resultado de pesquisas no campo das ciências sociais para as ciências médicas, ditas pela autora como uma ciência "dura". Embora o foco em discussão não sejam as tecnologias sociais, existe no artigo o entendimento de que elas sejam uma tecnologia para o social, ou seja, "projetos de programas de atenção ou de políticas de cuidado, [que] emergem de práticas de pesquisas inovadoras, não convencionais, mas que são, entretanto, técnicas de investigação das ciências sociais" (LUZ, 2011, p. 28). A conceituação desse trabalho sobre TS contempla o que é discutido na visão 2, principalmente a partir de uma aproximação com a discussão de Bava, atribuindo à TS uma tecnologia para o social.

O trabalho 5 apresenta como objetivo sistematizar aspectos conceituais dos termos técnica e tecnologia, destacando algumas implicações para o setor da saúde (LORENZETTI, 2012). O autor atribui ao termo tecnologia social o significado dado pela Rede de Tecnologia Social (RTS) que "compreende produto, técnica ou metodologia replicável, desenvolvida na interação com a comunidade e que represente efetiva solução de transformação social" (FUNDAÇÃO BANCODO BRASIL, 2009, p. 12). O posicionamento do autor aproxima-se do significado da visão 1, principalmente na discussão que é feita a partir dos trabalhos de Dagnino e colegas. 
O trabalho 6 relata oficinas realizadas por estudantes de diversas áreas do conhecimento dentro de escolas públicas. Nas palavras da autora, "o que aqui reunimos em 'Oficinas de Atividades' é fruto de diferentes processos e formatos de proposições que procuraram responder as demandas da própria escola e dos jovens" (LOPES, 2011, p. 280). Neste artigo, as tecnologias sociais são as oficinas de atividades que foram desenvolvidas, cuja função foi a "(re)construção de projetos e ampliação de redes de suporte junto a jovens advindos de grupos populares urbanos em situação de vulnerabilidade social" (LOPES, 2011, p. 288).

No sentido da construção social da tecnologia e da tecnologia para atender demandas sociais, a visão exposta pela autora de que as oficinas foram criadas dentro da escola com a participação efetiva de seus usuários e que muito foi realizado a partir do próprio projeto, este trabalho traz tanto a visão 1 como a visão 2 . Vale destacar que as conceituações presentes nos trabalhos de Dagnino destaca-se no trabalho de Lopes (2011).

O trabalho 9 propõe "modelar uma política de ensino que apresente um conjunto de atividades para a escola e para a sala de aula e que podem contribuir para o entendimento dos conflitos e para a resolução destes [...]" (CHRISPINO; SANTOS, 2011, p. 59). Para os autores, as tecnologias sociais são técnicas que poderiam mediar os conflitos em sala de aula e debater ideias discordantes. No sentido de procedimentos concluídos, para Chrispino e Santos (2011), a tecnologia social tem a "sinonímia" de uma tecnologia para ser utilizada em contextos sociais, se aproximando muito do sentido proposto por Bava.

Sobre os trabalhos comentados nesta segunda análise pode-se observar, ainda, a disposição temporal das publicações, sendo quatro publicações no ano de 2011 e uma publicação no ano de 2012. Observa-se que, das cinco obras, os trabalhos 5 e 6 utilizam o termo tecnologia social se aproximando mais do significado atribuído na visão 1 , enquanto os trabalhos 2 , 4 e 9 mostram mais evidentemente uma tecnologia para o social, ou seja, o uso de técnicas e procedimentos que podem modificar a sociedade.

Nessas duas primeiras análises, foi possível notar, principalmente pelos títulos de muitos trabalhos, que essas visões estavam diretamente relacionadas à algumas temáticas básicas recorrentes. Ou seja, muitos trabalhos traziam a discussão de desenvolvimento, outros de sustentabilidade, além de outros temas, como a teoria crítica. Como já tinha sido evidenciado duas visões para conceituação de TS no contexto brasileiro, foi realizada uma terceira análise visando identificar que temáticas básicas têm sido discutidas para o desenvolvimento dessas visões de TS.

\section{Terceira análise}

A terceira forma de busca, com o termo "tecnologia social", foi feita dia $1^{\circ}$ de setembro de 2015 , com artigos publicados entre os anos de 2011 e 2015 (últimos 5 anos), sendo a ocorrência do termo atribuída ao título do documento. O resultado exibiu 139 trabalhos e, após analise, 38 foram descartados, por estarem em duplicidade ou por apresentarem caminhos inválidos para visualização.

Foram analisados 101 trabalhos com a finalidade de agrupá-los. O critério utilizado para criar os grupos foi a base teórica utilizada e como o artigo tratava a Tecnologia Social como um conceito dentro das correntes previamente estabelecidas na primeira análise.

Na Figura 4 apresentam-se a disposição da quantidade de trabalhos e os grupos criados.

Figura 2 . Agrupamento dos artigos

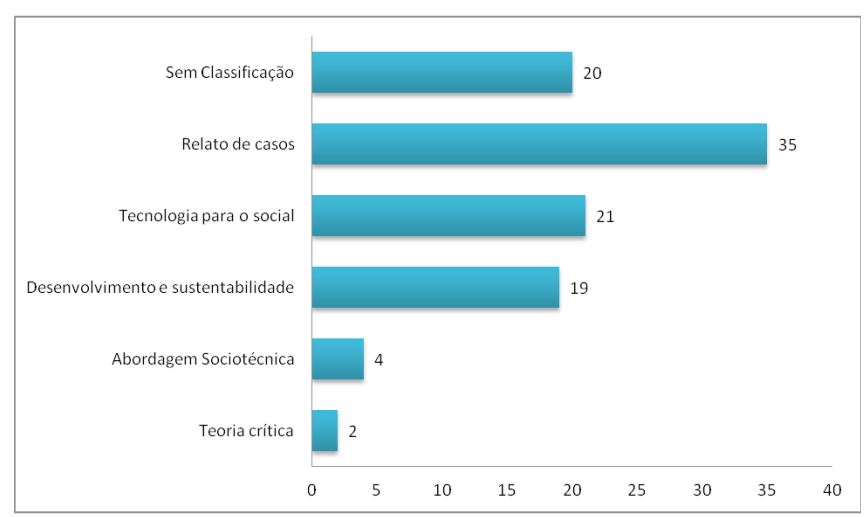

Fonte: Elaborado pelos autores.

O grupo com o nome "Sem classificação", com 20 trabalhos, corresponde a artigos que não apresentaram definição para o termo tecnologia social. Esse grupo é composto por resenhas e por trabalhos que debatiam sobre ciência e tecnologia num campo restrito a reflexões filosóficas, os quais correspondem a 19,8\% das obras analisadas. O grupo com o nome "Relato de casos", com 35 trabalhos, corresponde a 34,65\% 
do total, sendo composto de artigos que relatam o uso de tecnologias sociais. Trata-se de textos que pouco contribuem para a conceituação do termo.

O grupo com o nome "Tecnologia para o Social", com 21 trabalhos, representa 20,79\% do total. Esse grupo é composto de artigos que relatam a tecnologia social como uma tecnologia para o social, representando articulações, programas e artefatos que, introduzidos no ambiente social, podem melhorar a vida da sociedade.

O grupo denominado "Desenvolvimento e sustentabilidade" representou 18,81\% dos trabalhos. Esse grupo propõe que a tecnologia social seja uma forma de integração para a comunidade, não sendo apenas um artefato. Os autores desse grupo articulam a tecnologia social com a promoção de sustentabilidade e o desenvolvimento local.

O grupo com o nome "Abordagem Sociotécnica", com quatro trabalhos, representou apenas 3,96\% dos artigos. Os autores desse grupo defendem a adequação sociotécnica como forma de desenvolver teoricamente as tecnologias sociais, cuja análise deve integrar o social e o técnico, criando novas perspectivas conceituais (VALADÃO; ANDRADE; CORDEIRO NETO, 2014).

O último grupo, com o nome "Teoria Crítica", representa apenas 1,98\% dos trabalhos. Os autores desse grupo consideram que a tecnologia social deve ser controlada pelo homem e condicionada a valores. É utilizada para embasamento teórico a teórica crítica da tecnologia de Feenberg e a teoria crítica humanista radical de Guerreiro Ramos. A figura 3 mostra a relação de trabalhos que compõem os resultados da pesquisa. A coluna N. mostra a ordem de apresentação do trabalho na busca.

Tabela 3 . Relação de trabalhos que compõem os resultados da pesquisa.

\begin{tabular}{|c|c|c|c|}
\hline \multicolumn{4}{|c|}{ TEORIA CRÍTICA } \\
\hline $\mathbf{N}$. & Referência & & Citações \\
\hline 25 & SILVA, LUFT, MATOS, 2015. & 0 & \\
\hline 29 & FREITAS, SEGATTO, 2014. & 0 & \\
\hline \multicolumn{3}{|c|}{ ABORDAGEM SOCIOTÉCNICA } & \\
\hline N. & Referência & Citações & \\
\hline 4 & DAGNINO, 2011. & 2 & \\
\hline 5 & LIMA, DAGNINO, 2011; LIMA, DAGNINO, 2013. & 2 & \\
\hline 16 & $\begin{array}{l}\text { VALADÃO, ANDRADE, CORDEIRO NETO, } \\
2014 .\end{array}$ & 1 & \\
\hline 87 & DE JESUS, 2013. & 0 & \\
\hline \multicolumn{4}{|c|}{ DESENVOLVIMENTO E SUSTENTABILIDADE } \\
\hline N. & Referência & & Citações \\
\hline 14 & FREITAS, 2011. & & 1 \\
\hline 15 & BRITO DIAS, 2013. & & 1 \\
\hline 17 & JULIANO, 2013. & & 2 \\
\hline 18 & BONILHA, SACHUK, 2013. & & 2 \\
\hline 20 & SOARES FILHO, SOARES, 2014. & & 0 \\
\hline 26 & ROCHA SOBRINHO, 2011. & & 0 \\
\hline 31 & PEYLOUBET, FENOGLIO, CEJAS, 2013. & & 0 \\
\hline 36 & NEFFA, RITTO, DANIEL, 2011. & & 0 \\
\hline 39 & GAMA, MELLO, 2015. & & 0 \\
\hline 54 & MEDVEDOVSKI, SILVA, SOPEÑA, 2014. & & 0 \\
\hline 58 & PUPPI, 2013. & & 0 \\
\hline 59 & MURTA, 2014. & & 0 \\
\hline
\end{tabular}




\begin{tabular}{|c|c|c|}
\hline 61 & FREITAS, 2012. & 0 \\
\hline 68 & REZENDE, 2009. & 0 \\
\hline 70 & DE MELLO, CALLOU, 2013. & 0 \\
\hline 72 & FERNANDES, ACCORSSI, 2013. & 0 \\
\hline 73 & ADAMS, 2011 & 0 \\
\hline 84 & ALBUQUERQUE, 2011. & 0 \\
\hline 96 & CARRION, 2012. & 0 \\
\hline \multicolumn{3}{|c|}{ TECNOLOGIAS PARA O SOCIAL } \\
\hline N. & Referência & Citações \\
\hline 9 & DAMÁSIO, 2012. & 2 \\
\hline 10 & REIS, 2012. & 3 \\
\hline 28 & ISOTANI, 2014. & 0 \\
\hline 41 & SINGER, 2012. & 0 \\
\hline 43 & SANTOS, 2014 & 0 \\
\hline 44 & SANTO JUNIOR, OLIVEIRA, 2014. & 0 \\
\hline 48 & ALBUQUERQUE, 2013. & 0 \\
\hline 56 & PONTES, SANTOS, 2012, & 0 \\
\hline 60 & MAGALHÃES, 2011. & 0 \\
\hline 65 & GUZMÁN MUÑOZ, 2015. & 0 \\
\hline 66 & SAMPAIO, SAMPAIO FILHO, 2012. & 0 \\
\hline 69 & DAMÁSIO, 2014. & 0 \\
\hline 74 & FREITAS, 2011. & 0 \\
\hline 75 & FREITAS, 2013. & 0 \\
\hline 79 & SILVA, 2013. & 0 \\
\hline 83 & MAZZARO, 2011. & 0 \\
\hline 86 & MELLO, 2012. & 0 \\
\hline 90 & DIAS, SOARES, NEFFA, 2014. & 0 \\
\hline 93 & RITTO, ROJAS, 2001. & 0 \\
\hline 97 & MARQUES, 2013. & 0 \\
\hline 98 & RODRIGUES, 2015. & 0 \\
\hline
\end{tabular}

Fonte: Elaborado pelos autores.

Conclui-se pela existência da divisão dos trabalhos segundo as visões estabelecidas na primeira análise. Para a visão na qual a tecnologia social não é só um artefato, mas integra tudo que acontece na comunidade, têmse uma aproximação maior com relação aos trabalhos da Teoria Crítica, da Abordagem Sociotécnica e de Desenvolvimento e Sustentabilidade. Esta aproximação representou 54\% dos trabalhos. O grupo da visão tecnologia para o social, ou seja, articulações, programas e artefatos que introduzidos no ambiente social podem melhorar a vida da sociedade, teve uma aproximação maior, com $46 \%$ dos trabalhos.

\section{Discussão dos Resultados}

Após a leitura e a análise dos trabalhos da primeira busca, constatou-se que se evidenciam, no Brasil, duas visões teóricas sobre TS até certo ponto complementares. A primeira visão considera a Tecnologia Social não somente um artefato ou uma técnica, mas uma construção social que proporciona, para a comunidade, crescimento. Uma característica da tecnologia social desta corrente é que ela advém do conhecimento não científico, ou seja, 
do conhecimento popular. A tecnologia social descrita por Dagnino, por exemplo, é não prescritiva e se baseia em um processo aberto que pode ser modificado a cada reaplicação.

Cabe ressaltar que, na segunda análise, dois artigos versaram sobre as tecnologias sociais com o significado mais aproximado dessa primeira visão. Como a segunda análise atribuiu como critério o número de citações, o baixo retorno mostra a necessidade ainda de produções mais consistente com relação a conceituação de TS no Brasil. Com os resultados da terceira análise, evidenciou-se três aportes teóricos que muito se aproximam da primeira visão: a Teoria Crítica, as Abordagens Sociotécnicas e o Desenvolvimento e Sustentabilidade.

Para a Teoria Crítica, a tecnologia social deve ser controlada pelo homem e condicionada a valores. Para as Abordagens Sociotécnicas, a adequação sociotécnica é a forma de desenvolver teoricamente as tecnologias sociais e a análise das tecnologias sociais deve integrar o social e o técnico criando novas perspectivas conceituais (VALADÃO; ANDRADE; CORDEIRO NETO, 2014). E, para o desenvolvimento e a sustentabilidade, a tecnologia social é uma forma de integração para a comunidade, não sendo apenas um artefato, mas articulando a tecnologia social com a promoção de sustentabilidade e desenvolvimento local. As três abordagens de interpretação da tecnologia social formam um tripé que fundamenta a essência do conceito. Entende-se que não existe oposição entre esses aportes teóricos (teoria crítica, abordagens sociotécnicas e desenvolvimento e sustentabilidade), mas a junção dos pressupostos básicos de TS, conforme Figura 6.

Figura 3. Integração das correntes teóricas

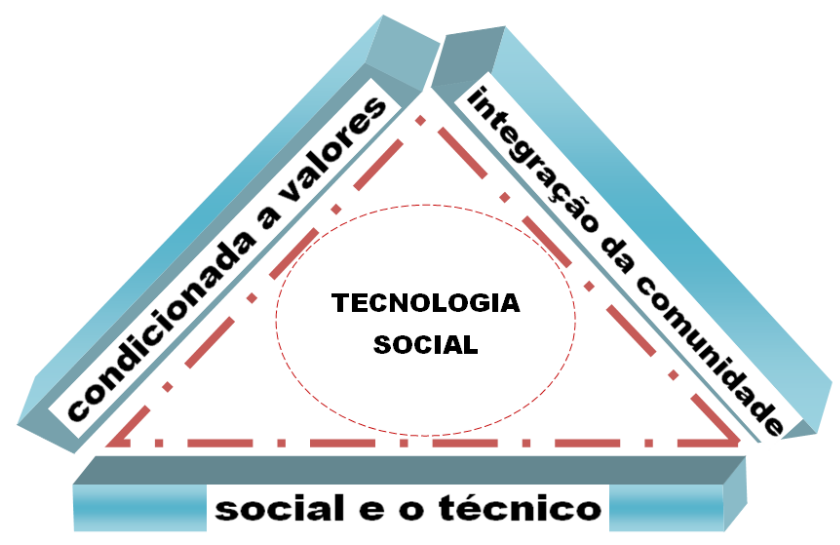

Fonte: Elaborado pelos autores.
A segunda visão identificada emprega o termo tecnologia social para identificar tecnologias para o social, ou seja, técnicas, programas e procedimentos, utilizados para reparar mazelas sociais das comunidades, seja no âmbito da saúde, educação ou segurança pública. Observa-se que, para essa visão, a palavra social é apenas um adjetivo para a tecnologia. Sílvio Caccia Bava foi um autor encontrado que têm, várias de suas definições de TS, aproximações com essa visão.

Convém evidenciar que, na segunda análise, apenas três trabalhos se alinharam mais à segunda visão e, já na terceira análise, 21 trabalhos. Esses autores, a exemplo de Bava, vislumbram que a palavra social é apenas um adjetivo para o termo tecnologia. Um resumo das três análises pode ser observado na Figura 7.

Figura 4 . Visões sobre TS encontradas na literatura.

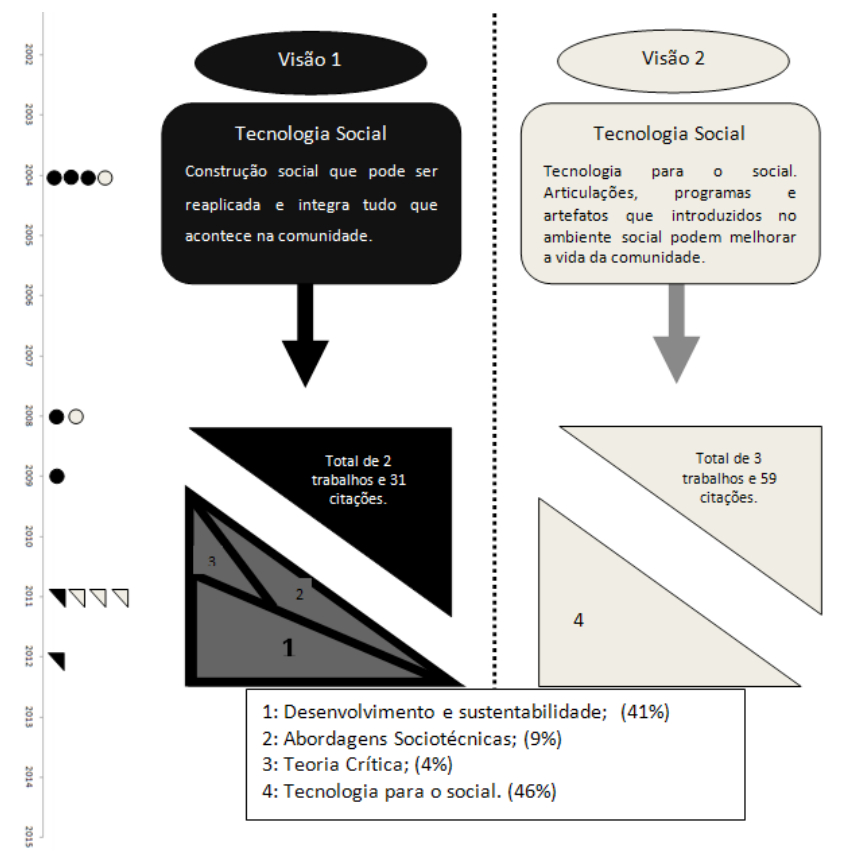

Fonte: Elaborado pelos autores.

O conceito de TS, desse modo, ainda se caracteriza por um conceito em formação, conforme pode ser visualizado a partir das duas visões de TS aqui apresentadas. Ora se aproximando mais de uma integração sociotécnica, como têm discutido principalmente autores como Renato Dagnino, ora se aproximando de uma tecnologia para o social, como se evidenciou em trabalhos como os de Caccia Bava. Mas, de modo geral, indiferente da visão, todos os trabalhos coadunam com uma visão muito particular 
para as TS. Como afirmam Rodrigues e Barbieri (2008, p. 1075), a TS “implica a construção de soluções de modo coletivo pelos que irão se beneficiar dessas soluções e que atuam com autonomia”. Além disso, como dizem Freitas e Segatto (2014, p. 312), a TS "rompe com a relação de dependência tecnológica [...] com o propósito de promover a transformação social, observadas as dimensões do desenvolvimento sustentável", constituindo-se numa "proposta de resgate à adequada relação entre ciência, tecnologia e sociedade". Esses pressupostos são comuns na literatura que têm discutido sobre TS no Brasil, conforme as leituras de todos os trabalhos aqui estudados se evidenciaram.

Apesar dos trabalhos aqui elencados, indiferente da visão, tratarem de uma nova forma de concepção tecnológica, como pode notar na análise de seu conteúdo, historicamente as visões que se aproximam de tecnologias para o social ainda têm dificuldades de se desvencilhar de uma visão mais utilitarista de produção do conhecimento científico. Vale destacar que os autores da visão 2 não coadunam com essa visão, mas a ideia de tecnologia para o social vincula-se, sobremaneira, a um paradigma cartesiano quantificável, dicotômico, sistemático e que privilegia o como em "detrimento de qual o agente ou qual o fim das coisas" (SANTOS, 2001, p. 16). O avanço científico, nesse sentido, tem pautado em uma tecnologia que promove a resolução dos problemas sociais, estejam os atores e a localidade, como um todo, imbricadas ou não a essas tecnologias.

Nessa perspectiva, o conhecimento científico e suas derivações tecnológicas promovem as transformações sociais a partir da geração de tecnologias de baixo custo, apropriadas ou alternativas aos contextos locais. As tecnologias apropriadas de Sarovaya Gandhi, intermediárias de Ernst Schumacher, democráticas de Lewis Mumford, dentre outras ao longo da histórica da evolução tecnológica mundial, mostram como sempre existiram esforços que procuraram superar essa visão e promover uma integração maior entre as dimensões natural, social, econômica, cultural, dentre outras da vida na terra. Assim como têm feito os autores da visão 2 aqui destacados.

As TS, na visão 1, por outro lado, é uma evidência de um paradigma emergente, como denominaram Santos (2000) e Plastino (2001), em que se vislumbra o início de uma "conscientização" (CAPRA, 2006) da ciência e da tecnologia para novas formas de desenvolvimento. As tecnologias, como destacou Ramos (1989), em vez de serem instrumentalidades para o desenvolvimento, passam, cada vez mais, a serem substantividades sociotécnicas, pressupondo uma concepção científica em que todas as ciências passam a ser consideradas sociais com apego e proximidade à ação humana, numa revalorização da racionalidade "estético-expressiva" (SANTOS, 2000) e estruturando uma nova forma de pensar a civilização, fundamentada na sua relação com a natureza.

As TS nessa visão, são tecnologias sociais pois partem da concepção de que natureza e sociedade compõe uma "hibridez" (LATOUR, 2000) da vida cotidiana. Povos, culturas, natureza e todas as formas de vida representadas em cada localidade são constituídas e constituintes da produção do saber, da construção das técnicas e do uso das instrumentalidades local. Quando a visão 1 trata as TS por meio de diferentes abordagens, como é o caso de "desenvolvimento e sustentabilidade", "abordagem sociotécnica" e "teoria crítica da tecnologia", tentam dar conta dessas diversas representações e como as tecnologias figuram em meio à integração cultura-natureza-sociedade.

\section{Conclusão}

Esse trabalho possibilitou a construção de um mapa teórico das publicações sobre tecnologias sociais entre os anos de 2002 e 2015 no Brasil. Grosso modo, foram identificadas, a partir de três análises realizadas, duas visões conceituais sobre TS. A primeira que trata das TS como práticas que proporcionam transformações sociais em uma comunidade a partir da ação da própria comunidade. A ideia de sociotécnico aparece nessa visão como uma indissociabilidade dos aspectos sociais, técnicos e materiais de uma determinada localidade. A segunda visão trata as TS como artefatos geradores de mudanças sociais. A introdução de programas, processos, produtos e metodologias adequados à realidade são consideradas TS quando geram transformações sociais condizentes com as aspirações da própria comunidade beneficiada. Essas duas visões permearam as conceituações existentes nos trabalhos analisados.

Desse modo, a produção científica sobre TS no Brasil tem caminhado com algumas características básicas. Uma delas é a existência de duas possibilidades de visualizar as TS. Por outro lado, essas visões não se apresentaram estanques nos trabalhos, muito pelo contrário, foi comum encontrar várias conceituações 
diferentes em uma mesma obra. Mais especificamente, contudo, alguns grupos, como visualizados a partir de Dagnino e Bava, têm discutido sobre as TS mais a partir de uma ou outra visão. Além disso, temáticas como desenvolvimento, sustentabilidade, abordagem sociotécnica, dentre outros, são centrais para a evolução do conceito. Os resultados mostrados também destacam a relevância da academia brasileira dar continuidade às discussões sobre TS hoje no País, principalmente visando consolidação de uma compreensão teórica do seu significado.

Contudo, o trabalho sugere que é preciso não somente discutir as TS e as diversas perspectivas conceituais que são possíveis extrair das produções atualmente existentes no País. Isso pois, essas perspectivas são oriundas de visões de mundo subjacentes a elas e que implicam nos delineamentos de seus objetivos e métodos. É possível dizer que as TS emergem dentro de uma nova visão de mundo, seja na academia ou fora dela. As TS para o social, como discutido na visão 2, são tentativas de superar os modelos convencionais, mas que acabam ainda carregando uma visão de mundo linear, cartesiana e utilitarista, ao pressupor que a Ciência a Tecnologia detém o saber-fazer necessário para o desenvolvimento de todos os povos e nações. Esse pressuposto fica evidente na necessidade ainda presente de introdução em localidades pobres de técnicas e artefatos produzidos laboratorialmente e cientificamente testados e provados, indiferentes da aceitação e validação desses artefatos por essas localidades. A visão 2 aqui discutida, apesar de trazer ainda essa nomenclatura, ao se aproximar de uma concepção genuína de TS hoje praticada no Brasil, acaba por afastar dessa concepção tecnológica e científica utilitarista.

As TS, por outro lado, como discutido na visão 1, mesmo distribuída conceitualmente em diversas perspectivas, como a perspectiva crítica, de sustentabilidade e sociotécnica, tem em seu arcabouço uma nova concepção paradigmática. Essa concepção busca superar as tradicionais formas de desenvolvimento, seja ele tecnológico, econômico ou científico, e passa a considerar resultado as produções locais, significadas e valorizadas a partir da própria hibridez inerente às relações sociais, naturais $\mathrm{e}$ culturais. A visão 1 apresentada a longo desse trabalho evidencia isso e propõe, principalmente no contexto brasileiro, uma nova forma de relação entre ciência e tecnologia e as diferentes formas de saberes, culturas e produções locais. Em vez de uma ciência e tecnologia a serviço do desenvolvimento, ou seja, para o social, tem-se transformações sociotécnicas significadas e representadas na ciência, na tecnologia, nos saberes locais, nas formas de organização, produção e muitas outras formas genuínas de geração de transformações locais a partir do próprio local e daquilo que lhe é inerente, como mostram os trabalhos aqui apresentados.

Como sugestão de trabalhos futuros, recomendase a realização de pesquisas orientadas a estudar os grupos de pesquisa sobre Tecnologias Sociais e suas diversas formas de fazer científico, com o propósito de aprofundar a análise e de explicar teoricamente a ligação das Tecnologias Sociais com a Abordagem Sociotécnica, com a Teoria Crítica e com o Desenvolvimento e Sustentabilidade, dentre outras abordagens latentes nacionalmente. Além disso, é preciso avançar no sentido de analisar as produções teóricas sobre o conceito para além do contexto brasileiro. Sabe-se que muito tem sido feito também no âmbito da América Latina que coaduna com a produção científica brasileira. Estudos que procurem identificar as características e especificidades teóricas internacionalmente pode contribuir para a consolidação conceitual local.

\section{Referências}

ABRANTES, P. As transições entre ciclos de ensino: entre problema social e objecto sociológico. Interações, Campo Grande, n. 1, p. 25-53, 2005.

AKUBUE, A. Appropriate technology for socioeconomic development in third world countries. Ejournals, winter-spring, 2000. Disponível em: $<$ http://scholar.lib.vt.edu/ejournals/JOTS/WinterSpring-2000/pdf/akabue.pd> Acesso em: 22 jul. 2011

ALBUQUERQUE, Lynaldo Cavalcanti de. Tecnologias Sociais ou Tecnologias Apropriadas? O Resgate de um Termo. In: OTTERLOO, Aldalice [et al.] orgs. Tecnologias Sociais: caminhos para a sustentabilidade. Brasília: RTS, 2009. p. 14-23.

ALVES, N.; CANÁRIO, R. Escola e exclusão social: das promessas às incertezas. Análise Social, Lisboa, v. 38, p. 981-1010, 2004.

ANDRADE, J. A.; VALADÃO, J. A. D. Análise da instrumentação da ação pública a partir da teoria do 
ator-rede: tecnologia social e a educação no campo em Rondônia. Revista de Administração Pública, v. 51, n. 3, 2017.

ARAÚjO, C. A. Bibliometria: evolução história e questões atuais. Em Questão, Porto Alegre, v. 12, n. 1, p. 11-32, jan./jun. 2006.

AYRES, J. R. C. M. Cuidado e reconstrução das práticas de saúde. Interface, Rio de Janeiro, v. 8, n. 14, p. 73-92, 2004.

BAVA, S. C. Tecnologia social e desenvolvimento local: tecnologia social: uma estratégia para o desenvolvimento. Rio de Janeiro: Fundação Banco do Brasil, 2004. p. 103-116.

BIGNETTI, L. P. As inovações sociais: uma incursão por ideias, tendências e focos de pesquisa. Ciências

Sociais Unisinos, São Leopoldo, v. 47, n. 1, p. 3-14, 2011.

BURGESS, J.; GREEN, J. You'Tube e a revolução digital. São Paulo: Aleph, 2009.

CANÇADO, A. C.; TENÓRIO, F. G.; PEREIRA, J. R. Gestão social: reflexões teóricas e conceituais. Cadernos EBAPE. BR, Rio de Janeiro, v. 9, n. 3, p. 681-703, 2011.

CAPRA, Fritjof. Ponto de Mutação. São Paulo: Cultrix, 2006.

CHRISPINO, A.; SANTOS, T. C. Política de ensino para a prevenção da violência: técnicas de ensino que podem contribuir para a diminuição da violência escolar. Ensaio, Rio de Janeiro, v. 19, n. 70, 2011. Disponível em: <http://www. scielo.br/scielo.php? script $=$ sci_arttext\&pid $=$ S010440362011000100005\&lng=pt\&nrm $=$ iso $>$. Acesso em: 1 maio 2015.

COSTA, A. B. (Org.). Tecnologia social e políticas públicas. Brasília: Fundação Banco do Brasil, 2013.

DAGNINO, R. O envolvimento da FBB com políticas públicas em tecnologia social: mais um momento de viragem. In: COSTA, A. B. Tecnologia social e políticas públicas. São Paulo: Fundação Banco do Brasil, 2013. p. 247-274.

\section{DAGNINO, R. A tecnologia social e seus} desafios: tecnologia social: uma estratégia para o desenvolvimento. Rio de Janeiro: Fundação Banco do Brasil, 2004. p. 187-210.
DAGNINO, R.; BRANDAO, F. C.; NOVAES, H. T. Sobre o marco analítico-conceitual da tecnologia social: tecnologia social: uma estratégia para o desenvolvimento. Rio de Janeiro: Fundação Banco do Brasil, 2004. p. 15-64.

DAGNINO, R. et al. Tecnologia social: ferramenta para construir outra sociedade. Campinas: Unicamp, 2009.

DIAS, R. D. B. O que é a política científica e tecnológica. Sociologias, Porto Alegre, v. 13, n. 28, p. 316-344, 2012.

FONSECA, R.; SERAFIM, M. A Tecnologia Social e seus arranjos institucionais. In: DAGNINO, Renato. (Org.). Tecnologia Social: Ferramenta para construir outra sociedade. SP: IG/UNICAMP, 2009.p. 139-153.

FREITAS, Cesar C. G.; SEGATTO, Andrea. P. Ciência, tecnologia e sociedade pelo olhar da tecnologia social: um estudo a partir da teoria crítica da tecnologia. Cadernos Ebape. V. 12, N. 2, p. 302320, 2014.

GARCIA, R. M. Tecnologia Apropriada: amiga ou inimiga oculta? Revista de Administração de Empresas, São Paulo, v. 27, n. 3, p.26-38, jul./set. 1987.

GARCIA, S. G. A tecnologia social como alternativa para a reorientação da economia. Estudos Avançados. V. 28, n. 82, p. 251-275, 2014.

GUIMARÃES, F. J.; FERREIRA FILHA, M. O. Repercussões da terapia comunitária no cotidiano de seus participantes. Revista Eletrônica de Enfermagem, Goiânia, v. 8, n. 3, p. 404-414, 2006.

GUIMARÃES, Y. A. F.; GIORDAN, M.

Instrumento para construção e validação de sequências didáticas em um curso a distância de formação continuada de professores. In: ENCONTRO NACIONAL DE PESQUISA EM EDUCAÇÃO EM CIÊNCIAS, 8., 2011, Campinas. Trabalhos Apresentados... Campinas: Unicamp, 2011.

GUPTA, A. K. et al. Mobilizing grassroots technological innovations and traditional knowledge, values and institutions: articulating social and ethical capital. Futures, Lincoln, UK, n. 35, p. 975-987, 2003. 
HALL, J.; MATOS, S.V.; MARTIN, M. J. C. Innovation pathways at the Base of the Pyramid: Establishing technological legitimacy through social attributes. Technovation, 34: 2014. pp 284-294.

HENDERSON, C. R. The scope of social technology. American Journal of Sociology, Chicago, v. 6, n. 4, p. 465-486, jan.1901.

KERSTENETZKY, C. L. Políticas sociais: focalização ou universalização. Revista de Economia Política, São Paulo, v. 26, n. 4, p. 104, 2006.

LATOUR, B. Ciência em ação: como seguir cientistas e engenheiros sociedade afora. São Paulo: UNESP, 2000.

LASSANCE, J. R. A. E.; PEDREIRA, J. S. Tecnologias sociais e políticas públicas: tecnologia social: uma estratégia para o desenvolvimento. Rio de Janeiro: Fundação Banco do Brasil, 2004. p. 65-82.

\section{LIANZA, S.; ADDOR, F. Tecnologia e}

desenvolvimento social e solidário. Porto Alegre: Universidade Federal do Rio Grande do Sul, 2005.

LINSINGEN, I. von. Perspectiva educacional CTS: aspectos de um campo em consolidação na América Latina. Ciência \& Ensino, Campinas, v. 1, p. 1-16, 2007.

LOPES, R. E. et al. Oficinas de atividades com jovens da escola pública: tecnologias sociais entre educação e terapia ocupacional. Interface Comunicação, Saúde, Educação, São Paulo, v. 15, n. 36, p. 277-288, 2011.

LORENZETTT, J. et al. Tecnologia, inovação tecnológica e saúde: uma reflexão necessária. Texto and Contexto Enfermagem, Florianópolis, v. 21, n. 2, p. 432, 2012.

LUZ, M. T. Especificidade da contribuição dos saberes e práticas das ciências sociais e humanas para a saúde. Saúde e Sociedade, São Paulo, v. 20, n. 1, p. 22-31, 2011.

MARTINS, L.; OSBERG, S. Social entrepreneurship: the case for definition. Stanford Social Innovation Review, Spring, p. 29-39, 2007.

MACLEAN, M.; HARVEY, C.; GORDON, J. Social innovation, social entrepreneurship and the practice of contemporary entrepreneurial philanthropy.
International Small Business Journal, 31(7), 2013. pp. 747-763.

OLIVEIRA, E. M. Empreendedorismo social no Brasil: atual configuração, perspectivas e desafiosnotas introdutórias. Revista FAE, Blumenau, v. 7, n. 2, p. 9-18, 2004.

PAULA, J. de. RTS - Novos desafios. In: OTTERLOO, Aldalice [et al.] orgs. Tecnologias Sociais: caminhos para a sustentabilidade. Brasília: RTS, 2009. p. 130-137.

PERES JÚNIOR, M. R.; PEREIRA, J. R. Abordagens teóricas da gestão social: uma análise de citações exploratória. Cadernos EBAPE.BR, Rio de Janeiro, v.12, n. 2, p. 221-236, 2014.

PEYLOUBET, P. et al. Desarrollo local a partir del uso de tecnología social: un enfoque alternativo. Cuardeno Urbano Espacio, Cultura, Sociedad. v. 9, n. 9, p. 170-191, 2010.

PLASTINO, C. A. O primado da afetividade: a crítica freudiana ao paradigma moderno. Rio de Janeiro: Relume-Dumará. 2001. p. 21-40.

PRAHALAD, C. K. A riqueza na base da pirâmide: como erradicar a pobreza com o lucro. Porto Alegre: Bookman, 2005.

PRAHALAD, C. K.; HART, S. L. The Fortune at the Bottom of the Pyramid. Strategy Business, 26 (1), 2002. pp 54-67.

RAMOS, A. G. A nova ciência das organizações: uma reconceituação da riqueza das nações. Rio de Janeiro: Fundação Getúlio Vargas, 1989.

RODRIGUES, I.; BARBIERI, J. C. A emergência da tecnologia social: revisitando o movimento da tecnologia apropriada como estratégia de desenvolvimento sustentável. Revista de Administração Pública, Rio de Janeiro, v. 42, n. 6, p. 1069-1094, 2008.

ROSE, N. Psicologia como uma ciência social.

Psicologia \& Sociedade, Belo Horizonte, v. 20, n. 2, p. 155-164, 2008.

RYBCZYNSKI, W. Paper heroes: a review of appropriate technology. Nueva York: Anchor Press/ Doubleday, 1980.

SANTOS, B. de S. A crítica da razão indolente: contra o desperdício da experiência. São Paulo: Cortez, 2000. p. 55-94 (Vol. 1). 
SCHUMACHER, E. F. O negócio é ser pequeno: um estudo de economia que leva em conta as pessoas. Rio de janeiro: Zahar, 1977. pp. 92-108.

SILVA, E. O Desenvolvimento de Tecnologias Sociais nas Universidades Públicas Estaduais do Paraná. 2012. Tese (Doutorado em Administração) Universidade Federal do Paraná.

SINGER, P. Economia solidária. Estudos avançados, São Paulo, v. 22, n. 62, p. 289-314, 2008.

SMALL, A. W. Seminar notes: the methodology of the social problem. American Journal of Sociology, EUA, v. 4, n. 1, p. 113-454, Jul. 1898.

THOMAS, H. De las tecnologias apropriadas a las tecnologias sociales: conceptos/estratégias/ diseños/acciones. Ponencia presentada al IV Seminario Ibero-Americano de Ciência Y Tecnologia do Centro Experimental de la Vivência da Economia. Córdoba: Argentina. Septiembre de 2009.

VALADÃO, J. A. D.; ANDRADE, J. A.;

CORDEIRO NETO, J. R. Abordagens sociotécnicas e os estudos em tecnologia social. Pretexto, Belo Horizonte, v. 15, n. 1, p. 44-61, jan/mar. 2014.

VALADÃO, J. A. D. Seguindo associações sociotécnicas sob a luz da teoria do ator-rede: uma tradução da pedagogia da alternância para rotinas e tecnologias sociais. 2014. 294 f. Tese (Doutorado em Administração) - Universidade Federal de Pernambuco, Recife, 2014.

VALADÃO, J. A. D.; SILVA, S. S. S. Justaposições da estratégia como prática e processo de estratégia: antes da visão pós-processual da estratégia. Revista de Administração Mackenzie, São Paulo, v. 13, n. 2, p.171-195, jan. 2012.

VILLAS-BÔAS, J. Manual tecnológico: mel de abelhas sem ferrão. Brasília: ISPN, 2012. 